\title{
Reactant Destabilization in the Bergman Cyclization and Rational Design of Light- and pH-Activated Enediynes ${ }^{\dagger}$
}

\author{
Igor V. Alabugin* and Mariappan Manoharan \\ Department of Chemistry and Biochemistry, Florida State University, Tallahassee, Florida 32306-4390
}

Received: August 13, 2002; In Final Form: October 22, 2002

\begin{abstract}
New ways to control the reactivity of enediynes are suggested on the basis of computational analysis of reactant destabilization in cyclic enediynes. This analysis is based on monitoring electronic changes in the Bergman cyclization along the internal reaction coordinate (IRC) path. Insight into the relative importance and timing of a variety of bond-forming and bond-breaking processes involving both in-plane and out-ofplane $\pi$-orbitals along the IRC path was gained using natural bond orbital (NBO) dissection. In the vicinity of the Nicolaou's threshold ( $3.20 \AA$ ) where the $\pi$-orbitals become parallel and their interaction pattern resembles that in the TS of the symmetry-forbidden thermal $[2 \mathrm{~s}+2 \mathrm{~s}]$ cycloaddition, the four-electron repulsive interaction of filled in-plane $\pi$-orbitals $\left(\pi_{\mathrm{i}}-\pi_{\mathrm{i}}\right)$ becomes a dominant destabilizing factor without any compensation from the bond-forming, attractive two-electron interaction of the in-plane $\pi$-orbitals $\left(\pi_{\mathrm{i}} \rightarrow \pi_{\mathrm{i}}^{*}\right)$. The dominant role of the interplay between attractive and repulsive interactions in the in-plane $\pi$-system is further illustrated by the observation that the reaction becomes truly spontaneous (barrierless) when the magnitude of the attractive two-electron interaction of in-plane $\pi-\pi^{*}$ orbitals becomes larger than that of the repulsive $\pi-\pi$ interaction. This theoretical analysis is applied toward a rational design of new highly reactive, $\mathrm{pH}$-activated acyclic enediynes and toward increasing the efficiency of the photochemical Bergman cyclization.
\end{abstract}

\section{Introduction}

The unusual cyclization of $(Z)$-enediynes with formation of benzene 1,4-diradicals ( $p$-benzynes), which was discovered by Robert Bergman several decades ago (Figure 1), ${ }^{1}$ has received much recent attention since the discovery of the biological activity of natural enediyne antibiotics in which production of the DNA damaging diradical is a key step. ${ }^{2}$ Control of enediyne reactivity is especially critical for biochemical applications in which enediynes need to produce diradical species at body temperature. The molecular architecture of natural enediyne antibiotics is complex, and their cyclization is usually triggered by a chemical reaction that activates the enediyne moiety toward the Bergman cyclization. On many occasions, strain relief in the transition state was suggested to account for the low activation energy of these Bergman cyclizations. ${ }^{3}$ Recently, a number of new applications were found for the Bergman cyclization (e.g., in materials science ${ }^{4}$ and in the synthesis of polycyclic aromatic compounds ${ }^{5}$ ). Understanding the electronic properties of the reaction intermediates is necessary for successful development of these applications, which explains the large number of theoretical studies that discuss the electronic properties of TS and $p$-benzyne diradical products of the Bergman cyclization. ${ }^{6-9}$

The Bergman cyclization is a typical representative of a more general class of cycloaromatization reactions, ${ }^{10}$ reactions that involve simultaneous formation of an aromatic system and a cyclic structure. Because a $\sigma$-bond is usually formed at the expense of two $\pi$-orbitals, a typical cycloaromatization reaction is also accompanied by formation of two radical centers.

\footnotetext{
† Part of the special issue "George S. Hammond \& Michael Kasha Festschrift"

* To whom correspondence should be addressed. E-mail: alabugin@ chem.fsu.edu.
}
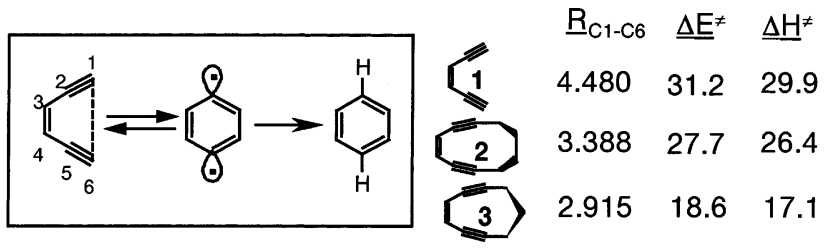

Figure 1. Bergman cyclization of 3-hexene-1,5-diyne 1 and the UB3LYP/6-31G** activation barriers for the cyclization of enediynes 1-3.

Because simultaneous formation of a conjugated (aromatic) system requires the presence of $\pi$-orbitals at every atom of the newly formed cycle, the presence of two (mutually perpendicular) $\pi$-orbitals at those atoms of the reactant that become connected by the new $\sigma$-bond is a prerequisite for any cycloaromatization reaction. These two $\pi$-systems, which can be either acetylenic or cumulenic, play distinctly different roles in cycloaromatization reactions, and understanding of these roles is crucial for control of cycloaromatization reactions. This was most clearly addressed in a recent study of Schreiner, Shaik, and co-workers in which the relative timing of changes in the in-plane and out-of-plane systems was analyzed using the valence bond (VB) theory. ${ }^{11}$ Changes in the in-plane orbitals were found to occur much earlier along the reaction path and control the activation energy of the cyclization. ${ }^{12}$ Very recently, Schleyer, Schreiner, and co-workers have thoroughly analyzed aromaticity of the $p$-benzyne products using a combination of thermodynamic arguments (isodesmic equations) and detailed dissected nucleus-independent chemical shift (NICS) computations on the product and the TS. ${ }^{13}$ Surprisingly, in seeming contradiction with the earlier studies, ${ }^{11}$ the dissected NICS values reported by these authors suggest that "cyclic electron 


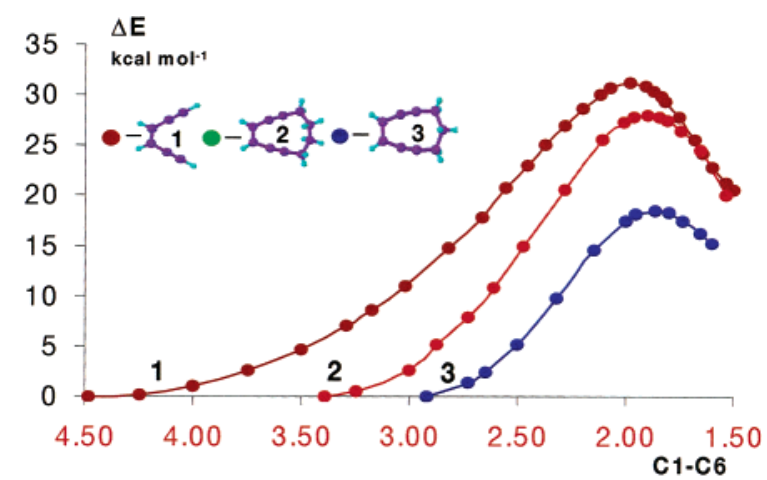

Figure 2. Internal reaction coordinate (IRC) computations for the Bergman cyclization of enediynes $\mathbf{1}-\mathbf{3}$.

delocalization in the TS occurs predominantly in the perpendicular $\pi$-system."14

Taking into consideration the apparent disparity between the two different estimates, we decided to revisit the question of the relative importance of in-plane and out-of-plane interactions using an approach that is different from that used in the previous studies. We will discuss our results briefly at the beginning of this paper. However, our main focus is complimentary to the bulk of published research, which dealt mainly with electronic properties of the TS and the diradical product of the Bergman cyclization. This paper rather concentrates on changes in the electronic structures in the reactants that accompany changes in the $\mathrm{C} 1-\mathrm{C} 6$ distance. The fine tuning of the reactant properties provides, arguably, the most efficient way to control kinetics of Bergman cyclization because it is intrinsically easier to control properties of reactants than those of transient reactive species and, ultimately, the reaction activation energy is simply the difference between the energies of the reactant and the TS.

We have chosen three well-known model enediynes $(\mathbf{1}-\mathbf{3})$ as a starting point in our discussion. The changes in electronic structure of these reactants are monitored along the internal reaction coordinate (IRC) path of the Bergman cyclization (Figure 2) with the help of natural bond orbital (NBO) analysis. ${ }^{15}$ In addition to the clear dissection of the in-plane and out-ofplane effects (which has already been achieved by Schreiner, Shaik, and co-workers ${ }^{11}$ ), it provides a dynamic picture reflecting the relative timing and importance of attractive and repulsive interactions in both the in-plane and out-of-plane $\pi$-systems of the enediyne moiety at the level of individual bonds. This is a novel analysis of the Bergman cyclization. We will discuss the applications of this analysis toward better understanding and control of photochemical Bergman cyclization and toward design of more reactive acyclic enediynes in the second and third parts of this paper.

\section{Details of The Computations and Method}

The unrestricted broken-spin B3LYP/6-31G(d,p) method, which has been shown to provide a sufficiently accurate description of the Bergman cyclization, ${ }^{16}$ was used for all geometry optimizations. ${ }^{17}$ For comparison, we also used the BLYP/6-31G(d,p) method, which gives barriers that are closer to the experimental data but shows the same reactivity trends (see Supplementary Information). ${ }^{18}$ Because it is not clear whether BLYP will remain superior to the more general hybrid B3LYP method for describing the behavior of substituted enediynes, we have chosen B3LYP/6-31G** as a basic level of theory in this work. Although the B3LYP method overestimates the reaction barriers and underestimates reaction endothermicity, this is acceptable because we are mostly interested in relative trends in reactivity. The internal reaction coordinate (IRC) computations were performed using the IRC option in Gaussian 98. The number of points and the step size were adjusted using STEPSIZE $=\mathrm{N}$ and $\mathrm{MAXPOINTS}=\mathrm{N}$ options. The electronic structures of the IRC points were analyzed using natural bond orbital (NBO) analysis. ${ }^{15}$ The NBO analysis involves sequential transformation of nonorthogonal atomic orbitals (AOs) to the complete and orthonormal sets of "natural" atomic orbitals (NAOs), hybrid orbitals (NHOs), and bond orbital (NBOs). These localized basis sets describe electron density and other properties by the smallest number of filled orbitals in the most rapidly convergent fashion. These orbital are closely related to the localized orbitals (bonds and lone pairs) used by organic chemists, and as a result, the NBO method developed by Weinhold and coauthors is becoming a powerful and popular method for study of bonding concepts. ${ }^{19,20}$ Reaction progress can be analyzed through the magnitude of interactions between the NBOs. In addition to allowing us to monitor the timing of electronic changes along the Bergman cyclization pathway, this method also provides a dissection of $\sigma / \pi$ and inplane/out-of-plane contributions ${ }^{21}$ to changes in the electronic structure of both the reactant and the TS. The NBO energetic analysis is a perturbative method based on the "best fit" localized Lewis structure, and thus, it becomes less meaningful for highly delocalized transition states. Therefore, the NBO interaction energies for the transition states should be taken only as a qualitative guide for estimating the general trends through a comparison within a family of related molecules.

\section{Results and Discussion}

The simple cyclic enediynes $\mathbf{2}$ and $\mathbf{3}$, which are much more reactive than the parent hex-3-ene-1,5-diyne $\mathbf{1}$, have received much attention as the most important prototypes for modeling the activating effect of strained cyclic structures. On the basis of empirical observations and MM2 calculations, Nicolaou et al. ${ }^{22}$ suggested that enhanced reactivity in simple cyclic enediynes is associated with shorter $\mathrm{C} 1-\mathrm{C} 6$ distances and that, when the $\mathrm{C} 1-\mathrm{C} 6$ distances fall within the critical range of 3.31$3.20 \AA,{ }^{23}$ the cyclization occurs at ambient conditions. Interestingly, ab initio computations of Kraka and Cremer showed that acceleration of the Bergman cyclization in these compounds can be modeled to a large extent (but not completely) by a simple decrease of the $\mathrm{C} 1-\mathrm{C} 6$ distance in enediyne $\mathbf{1}$ and, thus, the intrinsic properties of the enediyne moiety rather than the strain in the saturated $\left(\mathrm{CH}_{2}-\right)_{n}$ bridges account for a large part of the reactant destabilization. ${ }^{24}$

The B3LYP/6-31G** trends in the cyclization barriers and C1-C6 distances for the enediynes $\mathbf{1 - 3}$ are illustrated in Figures 1 and 2 with the latter providing the results of first internal reaction coordinate (IRC) computations of the Bergman cyclizations. $^{25}$ The general trends in reactivity are consistent with those reported previously. ${ }^{23}$ Interestingly, the relatively large decrease in the $\mathrm{C} 1-\mathrm{C} 6$ distance in 10-membered enediyne 2 results only in a moderate $(3.5 \mathrm{kcal} / \mathrm{mol})$ decrease in the activation energy, while the further (much smaller) decrease in the $\mathrm{C} 1-\mathrm{C} 6$ distance in the nine-membered enediyne $\mathbf{3}$ leads to a sharp $(9.1 \mathrm{kcal} / \mathrm{mol})$ drop in the activation energy for the cyclization. It is interesting to compare these energy changes with the intrinsic destabilization of the enediyne moiety given by the relative energies of the corresponding points (the same C1-C6 distances) at the IRC path for cyclization of parent compound 1. The $\mathrm{C} 1-\mathrm{C} 6$ distance decrease to $3.4 \AA$ in enediyne 1 increases the enediyne energy by $6 \mathrm{kcal} / \mathrm{mol}$, which shows that reactant destabilization in enediyne $\mathbf{2}$ does not translate 


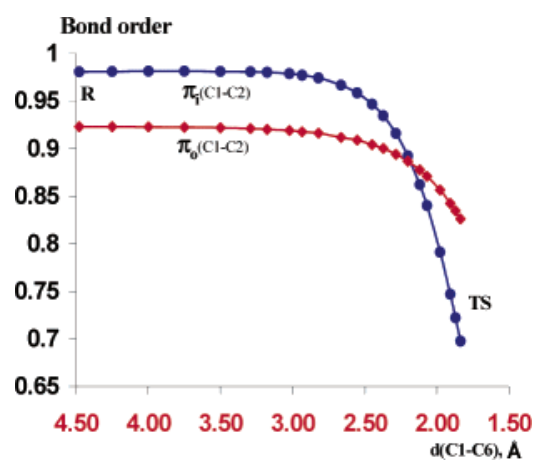

Figure 3. The changes in the NBO $\pi$-bond order of in-plane $\left(\pi_{\mathrm{i}}\right.$, and out-of-plane $\left(\pi_{0}, \downarrow\right)$ acetylenic bonds along the IRC pathway for the Bergman cyclization of enediyne $\mathbf{1}$.

completely to the decrease in activation energy $(3.5 \mathrm{kcal} / \mathrm{mol}){ }^{26}$ On the other hand, the $12.6 \mathrm{kcal} / \mathrm{mol}$ decrease in the activation energy for cyclization of nine-membered enediyne $\mathbf{3}$ relative to cyclization of parent compound $\mathbf{1}$ corresponds well to the intrinsic destabilization of enediyne moiety $(12 \mathrm{kcal} / \mathrm{mol})$.

As far as the intrinsic properties of the enediyne moiety are concerned, at least three destabilizing factors can a priori be associated with the initial stage of the cyclization-distortion/ breaking of the acetylenic bonds as a result of their bending, four-electron repulsion between the filled in-plane acetylenic $\pi$-orbitals, and the fact that, at a distance of ca. $3 \AA$, the inplane $\pi$-orbitals become parallel and reach a geometry that resembles the antiaromatic TS of the symmetry-forbidden $[2 \mathrm{~s}$ $+2_{\mathrm{s}}$ ] cycloaddition (vide infra). Although the importance of electron repulsion has been postulated for a long time, ${ }^{27}$ it has never been shown unambiguously and its role relative to bond breaking and antiaromaticity remains unclear. We were especially intrigued by the possibility that the cyclic enediynes are destabilized by antiaromaticity because of the fundamental importance of the aromaticity concept in organic chemistry 28 and the fact that antiaromatic molecules are rare but extremely interesting. ${ }^{29}$

Of the three destabilizing factors described in the Introduction, breaking the acetylene bonds is only of minor importance at the early reaction stage, as indicated by the negligible changes in the $\mathrm{C} 1-\mathrm{C} 2 \mathrm{NBO} \pi$-bond orders (both in-plane and out-ofplane) at C1-C6 distances above $3 \AA$ (Figure 3). Even at the TS, the $\pi$-bonds are only $30 \%$ broken. This resilience of the acetylenic $\pi$-bonds toward bending agrees well with the observation by Schreiner, Shaik, and co-workers that electronic changes in the Bergman cyclization lag behind the changes in geometry and that, as a result, the transition state for this endothermic reaction is $70 \%$ reactant-like electronically but $80 \%$ product-like geometrically. ${ }^{11}$

Unlike bond breaking, electron repulsion between the filled in-plane $\pi$-orbitals and decrease in the stabilizing $\pi-\pi^{*}$ interactions are indeed relevant to reactant destabilization and the increased reactivity of enediynes 2 and 3 . The trends in these interactions are illustrated in Figure 4. The repulsive fourelectron interaction between the occupied in-plane acetylenic $\pi$-orbitals is the largest and the most important contribution to the ground-state destabilization. This interaction increases continuously along the IRC path and accounts for the bulk of the energy increase in the early part of the reaction path. ${ }^{30}$

On the other hand, the stabilizing $\pi-\pi^{*}$ interactions that lead to formation of the $\mathrm{C} 1-\mathrm{C} 6 \sigma$ bond and to cleavage of the $\mathrm{C} 1-$ $\mathrm{C} 2$ and $\mathrm{C} 5-\mathrm{C} 6 \pi$-bonds, the changes most directly associated with the Bergman cyclization, ${ }^{31}$ display a more complicated pattern. The magnitude of the $\pi-\pi^{*}$ interactions decreases first, reaches zero at the at the $\mathrm{C} 1-\mathrm{C} 6$ distance of $3 \AA$ (very close to the Nicolaou's threshold!), and rapidly increases only after the threshold of $3 \AA$. This behavior is observed for the corresponding electronic interaction (Fock matrix) term, $F_{i j}$ (Figure 4), the overlap matrix element, $S_{i j}$ (Figure 4 ), and the combined energy of $\pi_{\mathrm{C} 1 \mathrm{C} 2} \rightarrow \pi^{*}{ }_{\mathrm{C} 5 \mathrm{C} 6}$ and $\pi_{\mathrm{C} 5 \mathrm{C} 6} \rightarrow \pi^{*}{ }_{\mathrm{C} 1 \mathrm{C} 2}$ interactions ${ }^{32}$ from the NBO deletion analysis (Figure 5).

The loss of the stabilizing $\pi-\pi^{*}$ interactions in cyclic enediynes may seem to be only a minor component of reactant destabilization (the energy of $\pi-\pi^{*}$ interactions in enediyne 1 is less than $0.5 \mathrm{kcal} / \mathrm{mol}$ ). However, the loss of the stabilizing interaction per se is not as important as the fact that these interactions do not increase at the reaction stage at which the destabilizing four-electron repulsive interactions increase steadily. As a result, an initial decrease of the $\mathrm{C} 1-\mathrm{C} 6$ distance in enediynes $\mathbf{1}$ and $\mathbf{2}$ results only in continuously increasing reactant destabilization without any compensation from the increased $\mathrm{C} 1-\mathrm{C} 6$ bonding. Only in the nine-membered enediyne 3 , the decrease in the $\mathrm{C} 1-\mathrm{C} 6$ distance results in an immediate increase in the extent of $\mathrm{C} 1-\mathrm{C} 6 \sigma$-bond formation. One may speculate that because the attractive $\pi-\pi^{*}$ curve is steeper than the repulsive $\pi-\pi$ curve in enediyne 3 the energy gain due to the bond formation increases faster than the energy penalty due to four-electron repulsion along the whole IRC path. ${ }^{33}$

In addition, this phenomenon is interesting from a conceptual point of view. NBO contours for the orbitals involved in the $\pi-\pi$ and $\pi-\pi^{*}$ interactions in Figure $6^{34}$ illustrate that the two acetylenic systems become nearly parallel at $\mathrm{C} 1-\mathrm{C} 6$ distances close to $3 \AA$ at which the positive overlap of the $\pi$-orbital with one of the $\pi^{*}$-nodes is compensated by a negative overlap with the other $\pi^{*}$-node (Figure $6 \mathrm{~b}$, bottom). This situation bears a striking resemblance to the interaction of two $\pi$-bonds in $D_{2 h}$ cyclobutadiene in which the $\pi-\pi^{*}$ interaction becomes zero while the $\pi-\pi$ repulsion is considerable (see Supporting Information), thus accounting for the extreme instability of this antiaromatic molecule. ${ }^{35}$ Even more relevant is a comparison with the TS of the symmetry-forbidden thermal $\left[2_{\mathrm{S}}+2_{\mathrm{s}}\right]$ cycloaddition (Figure 7), ${ }^{36}$ which prompted us to call this region "antiaromatic". 37

The "antiaromatic region" is not important for the reactivity of the parent enediyne $\mathbf{1}$ because the activation energy is determined only by the energy difference between the reactant and the TS. However, for the cyclic enediynes $\mathbf{2}$ and $\mathbf{3}$ (in which the $\mathrm{C} 1-\mathrm{C} 6$ distances are 3.39 and $2.92 \AA$, respectively), it is reasonable to expect that the "antiaromaticity" of the reactant would be relevant to the reaction kinetics.

The energies of the $\pi-\pi^{*}$ interactions in Figure 5 become extremely large at the vicinity of the TS indicating the new $\mathrm{C} 1-\mathrm{C} 6$ bond formation. At this region, the exact values of the NBO interaction energies are not meaningful, and the trends in Figure 5 should be used only for a qualitative discussion. Nevertheless, it is remarkable that for all enediynes in this study, the attractive $F_{i, j} \pi-\pi^{*}$ curve (which becomes steeper than the repulsive $\pi-\pi$ curve after the $3 \AA$ threshold) intersects the repulsive $\pi-\pi$ curve exactly at the TS. It is tempting to associate this observation with the fact that the cyclization becomes barrierless at shorter distances (after the intersection of the repulsive and attractive curves). A similar behavior is observed for the out-of-plane acetylenic $\pi$-orbitals, although the changes are less dramatic (Figure 4) and they occur at the later reaction stages in good agreement with the observations of Schreiner, Shaik, and co-workers. ${ }^{11}$ Certainly, there are many concurrent electronic changes in other parts of the molecule that accompany 

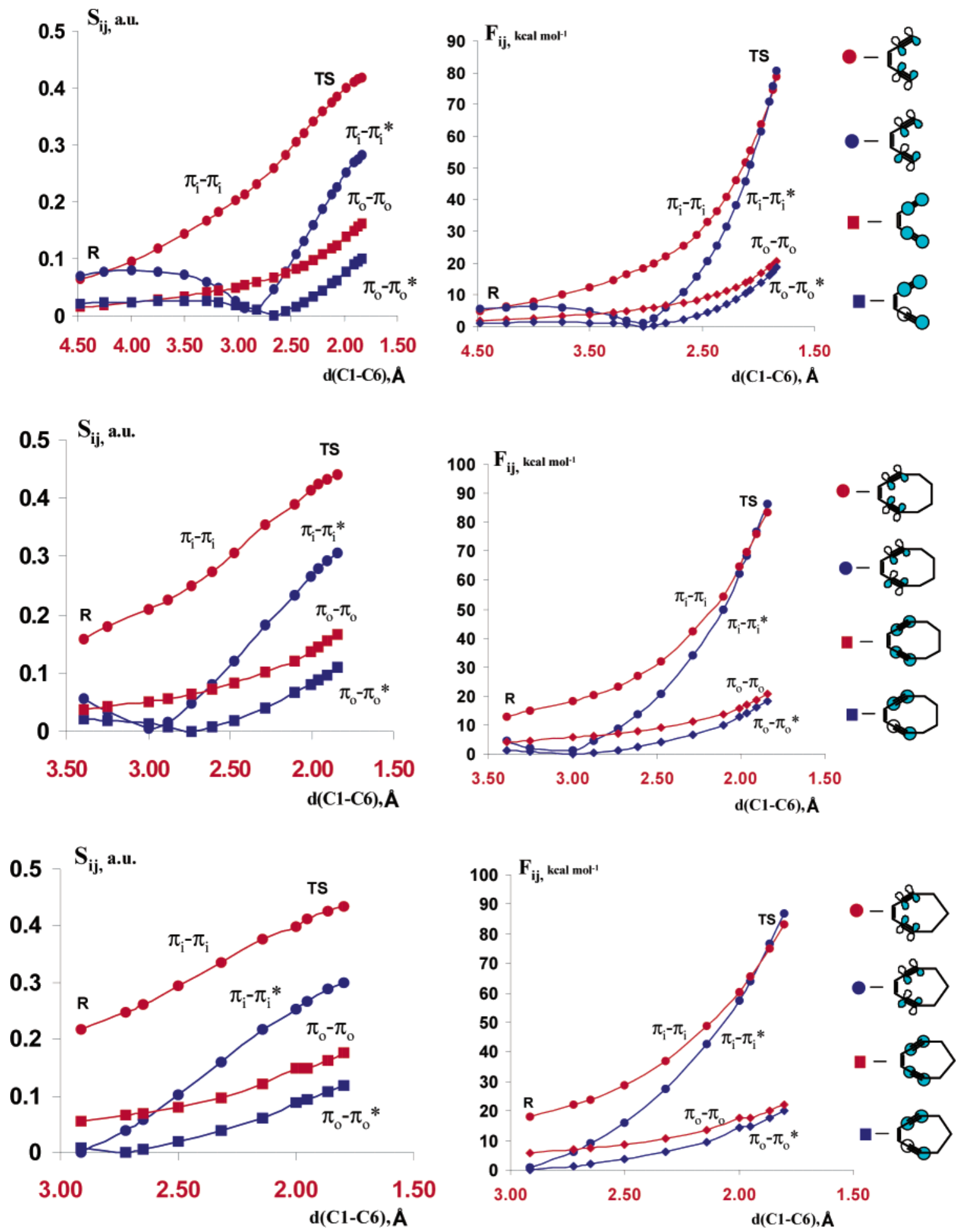

Figure 4. Changes in the overlap $\left(S_{i j}\right)$ and Fock $\left(F_{i j}\right)$ matrix elements of in-plane $\left(\pi_{\mathrm{i}}\right)$ and out-of-plane $\left(\pi_{\mathrm{o}}\right) \pi_{\text {- and }} \pi^{*}$-orbitals in enediynes $(\mathbf{1}, \mathbf{2}$, and 3) along the Bergman cyclization IRC.

the cyclization process, but those orbitals that are directly involved in the bond-breaking/bond-forming processes play the major role.

A first intriguing consequence from this analysis is that the photochemical version of the Bergman cyclization ${ }^{38-44}$ will be an efficient (and symmetry-allowed) ${ }^{45}$ process if the photochemical excitation involves the in-plane orbitals as shown by the arrow in Figure 8. Because such excitation promotes an electron from a $\mathrm{MO}$ that is $\mathrm{C} 1-\mathrm{C} 6$ antibonding to a $\mathrm{MO}$ that is $\mathrm{C} 1-\mathrm{C} 6$ bonding, the excitation should increase the $\mathrm{C} 1-\mathrm{C} 6$ bonding at a relatively early reaction stage. Moreover, a simple inspection of the MO correlation diagram (to the best of our knowledge, a first published correlation diagram of this reaction that includes both $\pi$-systems of enediyne moiety) suggests that the "in-plane excited state" may transform barrierlessly into an excited state of the product. Unfortunately, in simple enediynes, "in-plane" excitation requires much more energy than the excitation of the out-of-plane orbitals ${ }^{46}$ and is hardly accessible experimentally.

This analysis suggests that the efficiency of the photochemical Bergman cyclization can be increased by delivering excitation to the in-plane orbitals by, for example, decreasing the energy 


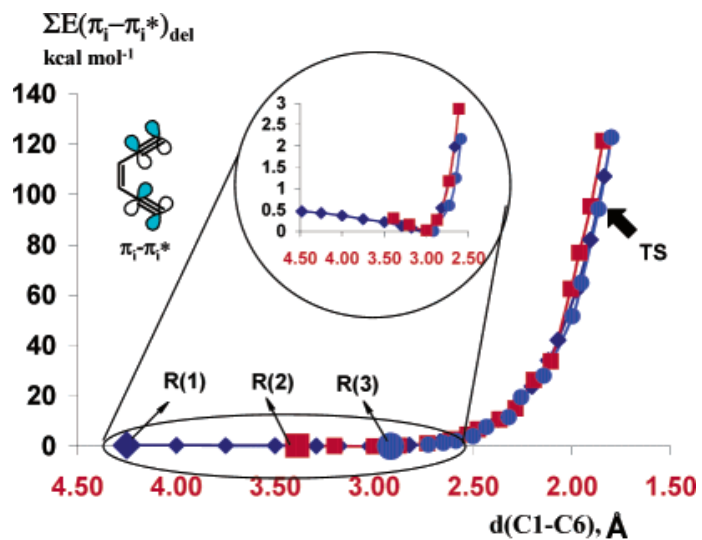

Figure 5. Changes in the energy of in-plane $\pi-\pi^{*}$ interactions $\left(E_{\pi-\pi^{*}}\right)$ along the IRC pathways for the Bergman cyclization of enediynes $\mathbf{1 - 3}$ (the calculated points for compounds $\mathbf{1 - 3}$ are shown as $\boldsymbol{\nabla} \mathbf{\square}$, and $\boldsymbol{\bullet}$. respectively). $\underline{\mathbf{a}}$
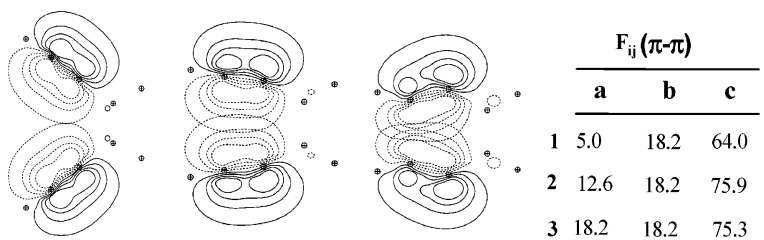

$\begin{array}{lll}12.6 & 18.2-75.9\end{array}$

$\begin{array}{llll}3 & 18.2 & 18.2 & 75.3\end{array}$
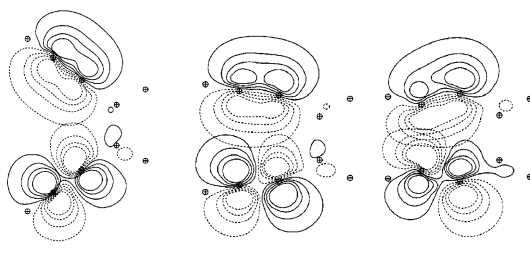

\begin{tabular}{cccc} 
& \multicolumn{3}{c}{$\mathbf{F}_{\mathrm{ij}}\left(\pi-\pi_{\boldsymbol{n}}\right)$} \\
\cline { 2 - 4 } $\mathbf{a}$ & $\mathbf{a}$ & $\mathbf{b}$ & $\mathbf{c}$ \\
\cline { 2 - 4 } $\mathbf{5 . 7}$ & 1.3 & 61.5 \\
$\mathbf{2}$ & 4.4 & 1.3 & 76.6 \\
$\mathbf{3}$ & 0.6 & 0.6 & 76.7
\end{tabular}

$\begin{array}{ll}1 & 0.47\end{array}$

20.31

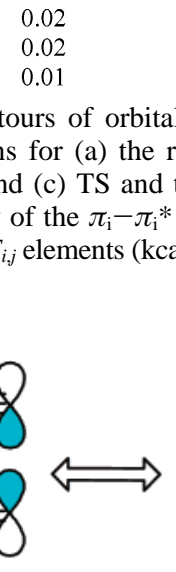

61.93

95.31

94.29
Figure 6. NBO contours of orbitals involved in the in-plane $\pi-\pi$ and $\pi-\pi^{*}$ interactions for (a) the reactant, (b) IRC point at $\sim 3 \AA$ C1-C6 separation, and (c) TS and the corresponding Fock elements along with the energy of the $\pi_{\mathrm{i}}-\pi_{\mathrm{i}}^{*}$ interaction estimated by deletion of the corresponding $F_{i, j}$ elements $\left(\mathrm{kcal} \mathrm{mol}^{-1}\right)$ followed by recalculation of the wave function.

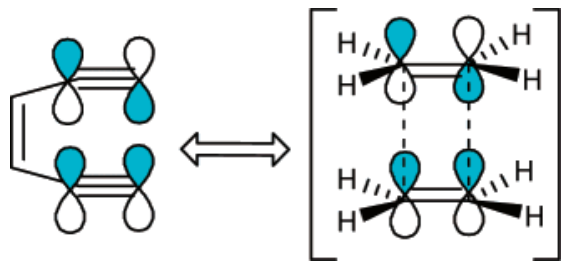

Figure 7. Comparison of the "antiaromatic region" (i.e., the in-plane $\pi-\pi^{*}$ interaction pattern at $\sim 3 \AA \mathrm{C} 1-\mathrm{C} 6$ distance) with the antiaromatic TS of the $\left[2_{\mathrm{s}}+2_{\mathrm{s}}\right]$ cycloaddition.

gap between the in-plane frontier MOs. A possible route to decreasing the energy gap is to include the enediyne moiety in a strained 10-membered ring (Figure 9). Decrease in the C1C6 distance destabilizes the occupied MO in which the interaction between the end orbitals is antibonding and, at the same time, stabilizes the empty MO in which the $\pi^{*}$-orbitals overlap constructively. This decreases the energy gap between the in-plane $\pi$ - and $\pi^{*}$-MOs, and in excellent agreement with this analysis, the most efficient photo-Bergman cyclizations reported in the literature involve cyclic enediynes. ${ }^{40,41,43}$

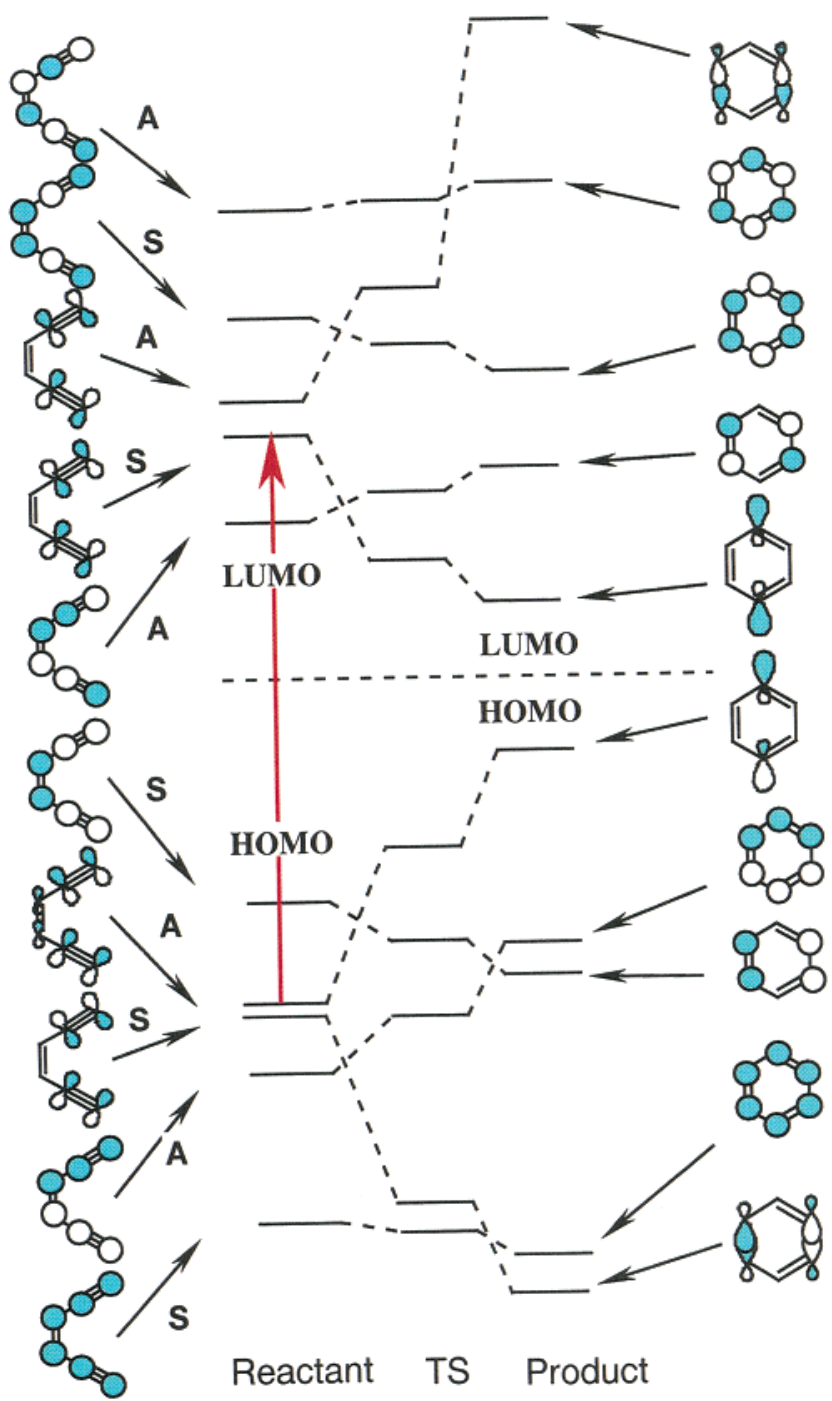

Figure 8. Correlation diagram illustrating the relative changes in the in-plane and out-of-plane orbitals in TS of the Bergman cyclization (B3LYP/6-31G**). ${ }^{47}$
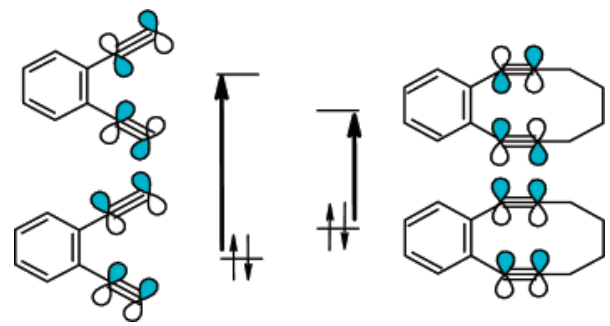

Figure 9. Effect of locking enediyne moiety in a cycle on the energy gap between frontier in-plane MOs.

This theoretical analysis can also be applied to the rational design of more efficient thermal cyclizations. If four-electron repulsion is the dominant factor in the reactant destabilization, any structural perturbation that either increases electron repulsion in the reactant or decreases the electron repulsion in the TS will decrease the activation energy of the cyclization.

We suggest that such a decrease in repulsive interactions can be achieved by placing an acceptor substituent in the proximity of the acetylenic in-plane $\pi$-orbitals. One example is the recent report of a large accelerating effect caused by $\sigma$-withdrawing substituents directly attached to the acetylenic termini of the enediyne moiety, ${ }^{48}$ in contrast to the decelerating effect of these substituents at the more remote (vinylic) positions. ${ }^{49}$ Another 
TABLE 1: Calculated Energetics for the Bergman Cyclizations of Protonated and Unprotonated Aminoenediynes

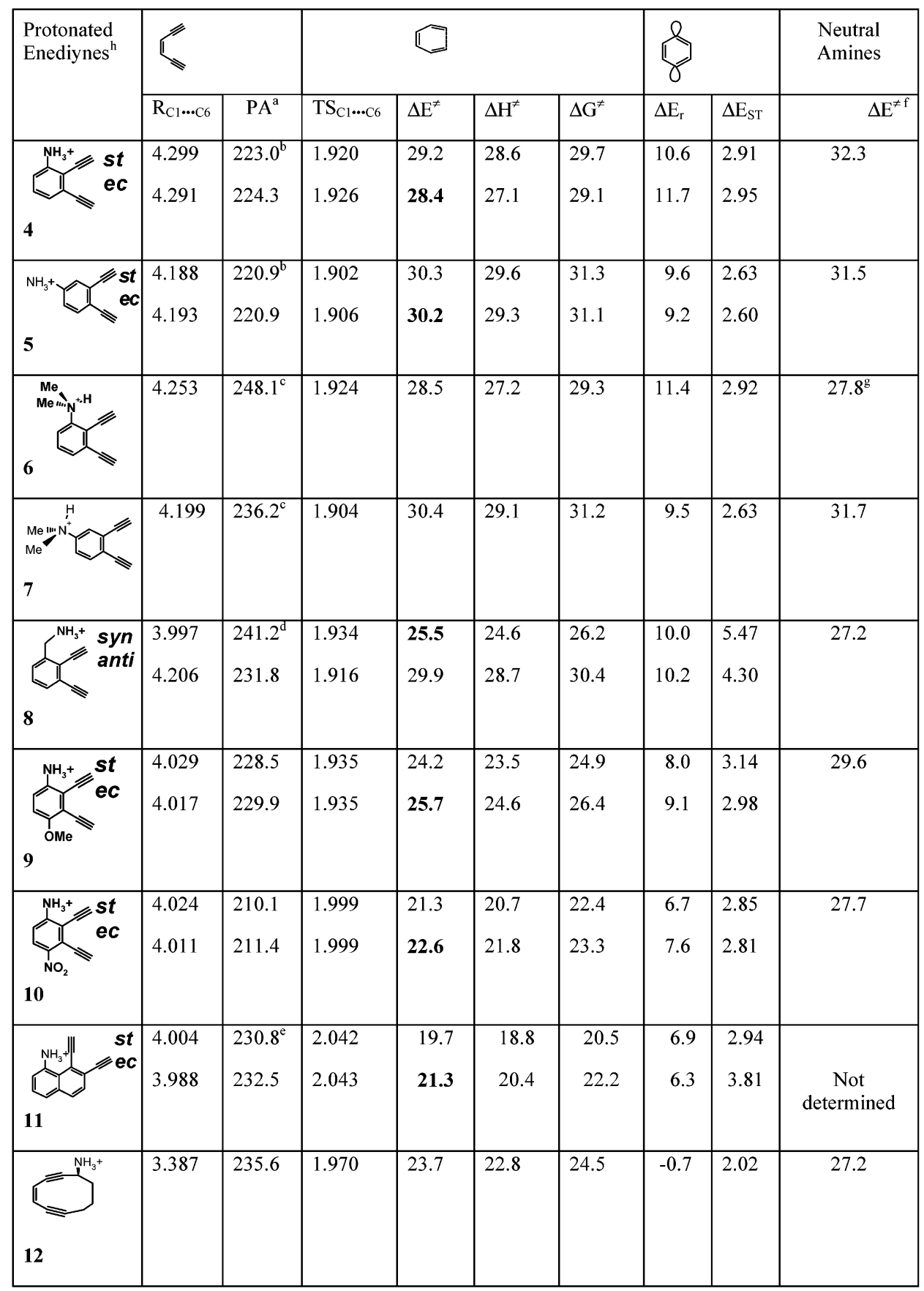

${ }^{a}$ The gas-phase proton affinity for related amino compounds. ${ }^{b} \mathrm{PA}\left(\mathrm{PhNH}_{2}\right)=224.4 \mathrm{kcal} \mathrm{mol}^{-1} \cdot{ }^{c} \mathrm{PA}\left(\mathrm{Me}_{2} \mathrm{NH}\right)=240.7 \mathrm{kcal} \mathrm{mol}{ }^{-1} .{ }^{d} \mathrm{PA}\left(\mathrm{MeNH}_{2}\right)$ $=230.6 \mathrm{kcal} \mathrm{mol}{ }^{-1}$, and $\mathrm{PA}\left(\mathrm{PhCH}_{2} \mathrm{NH}_{2}\right)=235.2 \mathrm{kcal} \mathrm{mol}^{-1} \cdot{ }^{e} \mathrm{PA}(1$-aminonaphthalene $)=227.7 .{ }^{f}$ The reaction barriers for the corresponding neutral amino enediynes. ${ }^{g}$ The neutral amine 9 has a lower activation energy because of the reactant destabilization by steric interaction of the bulky $\mathrm{NMe}_{2}$ substituent with the adjacent acetylene moiety in the most stable (planar) reactant conformation. "st" stands for staggered and "ec" for eclipsed.

way for placing an accelerating substituent in direct spatial proximity to the in-plane $\pi$-orbitals is to use appropriate ortho substituents in benzannelated enediynes. Recently, we have shown that ortho substituents exert a large effect on the cyclization rate and proposed that this observation can be used for the design of $\mathrm{pH}$-sensitive enediynes. ${ }^{50}$ The acid-catalyzed Bergman cyclizations are interesting because cancer cells are more acidic ( $\mathrm{pH} \mathrm{5.5)})^{51}$ than normal cells $(\mathrm{pH} 7.5) .{ }^{52}$ Thus, the significant increase in reactivity upon protonation can be used in the design of tumor-specific DNA cleaving agents. ${ }^{52,53}$

Table 1 provides examples of amino enediynes that become much more reactive toward the Bergman cyclization upon protonation on nitrogen. Clearly, the presence of a positively charged ammonium moiety alleviates the $\pi-\pi$ repulsion of the in-plane $\pi$-orbitals as illustrated in Figure $10 .^{54}$

The computational results given in Table 1 illustrate that acceleration of the Bergman cyclization by protonation of a spatially close amino group is a general phenomenon. Because the accelerating effect of ammonium groups is transmitted mainly through space, such a group can be placed either at the vinyl or at the acetylenyl regions, and there are several promising structural classes of amino enediynes with a wide range of basicity and reactivity that can be activated through protonation. Comparison of the calculated activation energies for ortho- 

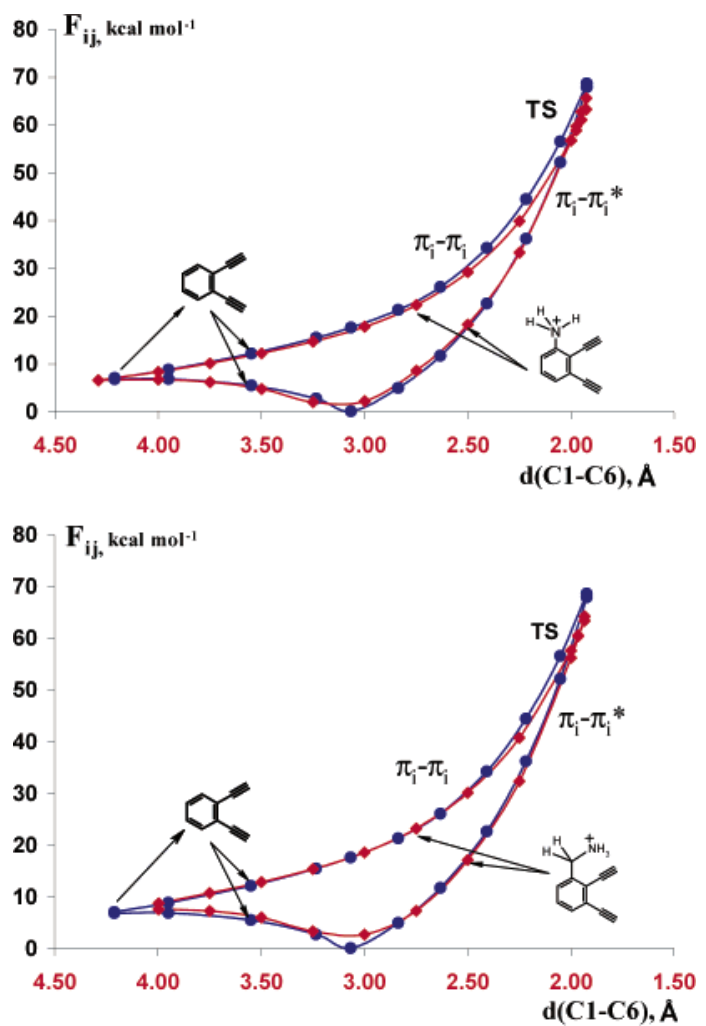

Figure 10. Comparison of relative changes in the magnitudes of attractive and repulsive in-plane $\pi$-interactions along the IRC pathway of the Bergman cyclization of enediynes $\mathbf{4}$ and $\mathbf{8}(\checkmark)$ with those for the cyclization of 1,2-diethynyl benzene ( $)$.

substituted enediynes with those for the 10-membered enediyne 2 shows that several of the proposed acyclic enediynes are sufficiently reactive to be used for biological applications.

For example, amino-nitro-enediyne $\mathbf{1 0}$ (which should be comparable in reactivity to the cyclic enediyne $\mathbf{2}$ even in the neutral form) is predicted to become ca. 50000 times more reactive when protonated (ca. a 20 million fold increase in reactivity in comparison with 1,2-diethynylbenzene!). Interestingly, both donor (syn-OMe in 9) and acceptor $\left(\mathrm{NO}_{2}\right.$ in 10) substitution can increase the accelerating effect of ortho ammonium group when the steric interference with the above substituents "pushes" the adjacent acetylene moiety toward the other acetylene group increasing the $\mathrm{C} 1-\mathrm{C} 6$ bonding. This is an example of an interesting cooperative effect between two ortho substituents further illustrated in Figure 11.55

The benzylamine $\mathbf{8}$ is particularly interesting because the enhancement in its reactivity upon protonation depends on the conformation of the reactant. The more reactive syn conformer is also $1.4 \mathrm{kcal} / \mathrm{mol}$ more stable in the gas phase because of a stabilizing $\pi \rightarrow \sigma^{*}(\mathrm{~N}-\mathrm{H})$ interaction. Certainly, the solvation effects in solution and molecular recognition inside of the DNA will change the relative energies of the conformers. Although a thorough and extended discussion of these effects goes beyond the scope of this paper, one can envision a system in which binding to DNA is conformer-specific (e.g., for the syn conformer of $\mathbf{8}$ ). This may provide an additional mechanism for enhancing reactivity and selectivity of DNA-cleaving enediyne drugs.

Finally, the increased reactivity of enediyne $\mathbf{1 2}$ confirms that the accelerating effect of protonated amino groups can be successfully combined with the other ways to control the Bergman cyclization, for example, by incorporating the enediyne moiety into a strained cycle. Although presence of an $\alpha$-amino group in $\mathbf{1 2}$ leads only to a minor increase in reactivity compared to that of enediyne $2(0.5 \mathrm{kcal} / \mathrm{mol}$ decrease in the activation energy), protonation of this group provides a significant further increase in reactivity.

\section{Conclusion}

The electronic changes in the in-plane and out-of-plane $\pi$-orbital interactions during the course of the Bergman cyclization are clearly manifested by the NBO analysis of model and de novo designed $\mathrm{pH}$-activated enediynes. This analysis puts the Bergman cyclization in a new context as an asynchronous $[2+2]$ addition interrupted at the 1,4-diradical stage by aromatic (benzene) stabilization. Although complete understanding of reactivity of substituted enediynes should also include electronic changes in other parts of the molecules in addition to the electronic properties of the enediyne system per se, the theoretical results described in this paper should provide a foundation for better understanding of enediyne chemistry and photochemistry. In further studies, this analysis can be complemented with monitoring of electronic changes in other parts of the molecule.

This theoretical analysis suggests that the efficiency of the photochemical Bergman cyclization can be increased by decreasing the energy gap between the in-plane frontier $\pi$-orbitals.

This paper also affords several intriguing predictions regarding electronic control in the Bergman cyclization such as a large accelerating effect of protonated ortho substituents that are spatially proximal to the in-plane $\pi$-orbitals. Because the accelerating effect of an ammonium group is transmitted mainly through space, such a group can be placed either at the vinyl or at the acetylene regions, and there are several promising structural classes of amino enediynes with a wide range of basicity and reactivity that can be activated through protonation.

Finally, to the best of our knowledge, this paper provides a first application of $\mathrm{NBO}$ analysis to following the electronic changes along internal reaction coordinate, which allows disentangling the interplay between repulsive and attractive interactions and monitoring relative timing of changes in the

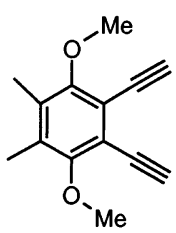

13, $E_{\mathrm{a}}=25.6$

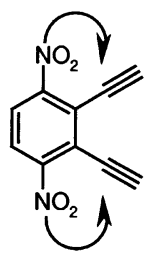

$14, E_{a}=25.5$

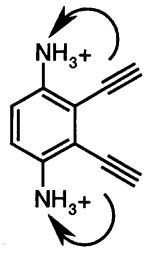

$15, E_{\mathrm{a}}=30.8$

Pull-pull

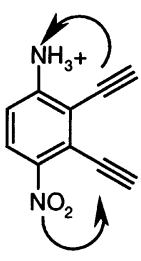

$10, E_{\mathrm{a}}=22.6$

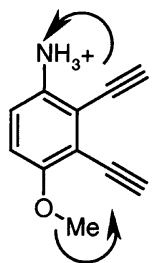

9, $E_{a}=25.7$

Push-push

Figure 11. Predicted cooperative effects on activation energies (in kcal/mol) at the B3LYP/6-31G** level for model enediynes ("push" and "pull" denote through-space repulsive (steric) and attractive (H-bonding) interactions of ortho substituents with in-plane $\pi$-orbitals of an adjacent acetylene moeity). 
in-plane and out-of-plane $\pi$-systems in an archetypal cycloaromatization reaction.

Acknowledgment. I.A. is grateful to Florida State University for a First Year Assistant Professor Award and to the donors of the American Chemical Society Petroleum Research Fund for partial support of this research. This paper is dedicated to Professor Michael Kasha, a wonderful colleague and a source of inspiration and knowledge, on the occasion of his 80th birthday.

Supporting Information Available: Cartesian coordinates of all stationary point geometries, NBO analysis of $\pi-\pi$ and $\pi-\pi^{*}$-interactions along the IRC cyclizations paths, NBO analysis of $\pi-\pi$ and $\pi-\pi^{*}$-interactions in cis-butadiene and cyclobutadiene, and the nucleus-independent chemical shift (NICS) changes along the IRC cyclizations pathways. This material is available free of charge via the Internet at http:// pubs.acs.org.

\section{References and Notes}

(1) Jones, R. R.; Bergman, R. G. J. Am. Chem. Soc. 1972, 94, 660. Bergman, R. G. Acc. Chem. Res. 1973, 6, 25.

(2) Nicolaou, K. C.; Smith, A. L. Acc. Chem. Res. 1992, 25, 497. Maier, M. E.; Bosse, F.; Niestroj, A. J. Eur. J. Org. Chem. 1936, 1, 1. Grissom, J. W.; Gunawardena, G. U.; Klingberg, D.; Huang, D. Tetrahedron 1996, 19, 6453. Fallis, A. G. Can. J. Chem. 1929, 7, 159. Caddick, S.; Delisser, V. M.; Doyle, V. E.; Khan, S., Avent, A. G.; Vile, S. Tetrahedron 1999, 55, 2737. Enediyne Antibiotics as Antitumor Agents; Borders, D. B., Doyle, T. W., Eds.; Marcel Dekker: New York, 1995. Gleiter, R.; Kratz, D. Angew. Chem. 1993, 105, 884.

(3) See also: Magnus, P.; Carter, P.; Elliott, J.; Lewis, R.; Harling, J.; Pitterna, T.; Bauta, W. E.; Fortt, S. J. Am. Chem. Soc. 1992, 114, 2544. Snyder, J. P. J. Am. Chem. Soc. 1990, 112, 5367.

(4) Chen, X.; Tolbert, L. M.; Hess, D. W.; Henderson, C. Macromolecules 2001, 34, 4104. Shah, H. V.; Babb, D. A.; Smith, D. W., Jr. Polymer 2000, 41, 4415. John, J. A.; Tour, J. M. J. Am. Chem. Soc. 1994, 116, 5011.

(5) Bowles, D. M.; Palmer G. J.; Landis, C. A.; Scott, J. L.; Anthony, J. E. Tetrahedron 2001, 57, 3753. Bowles, D. M.; Anthony, J. E. Org. Lett. 2000, 2,85 .

(6) (a) Scheiner, A. C.; Schaefer, H. F., III; Liu, B. J. Am. Chem. Soc. 1989, 111, 3118. (b) Nicolaides, A.; Borden, W. T. J. Am. Chem. Soc. 1993, 115, 11951. (c) Lindh, R.; Persson, B. J. J. Am. Chem. Soc. 1994, 116 , 4963. (d) Lindh, R.; Lee, T. J.; Bernhardsson, A.; Persson, B. J.; Karlström, G. J. Am. Chem. Soc. 1995, 117, 7186. (e) Kraka, E.; Cremer, D.; Bucher, G.; Wandel, H.; Sander, W. Chem. Phys. Lett. 1997, 268, 313. (f) Lindh, R.; Ryde, U.; Schutz, M. Theor. Chem. Acc. 1997, 97, 203. (g) McMahon, R. J.; Halter, R. J.; Fimmen, R. L.; Wilson, R. J.; Peebles, S. A.; Kuczkowski, R. L.; Stanton, J. F. J. Am. Chem. Soc. 2000, 122, 939. (h) Jones, G. B.; Warner, P. M. J. Am. Chem. Soc. 2001, 123, 2134.

(7) Cramer, C. J. J. Am. Chem. Soc. 1998, 120, 6261. Johnson, W. T. G.; Sullivan, M. B.; Cramer, C. J. Int. J. Quantum Chem. 2001, 85, 492508. Johnson, W. T. G.; Cramer, C. J. J. Phys. Org. Chem. 2001, 14, $597-$ 603. Cramer, C. J.; Thompson, J. J. Phys. Chem. A 2001, 105, 20912098. Kraka, E.; Cremer, D. J. Comput. Chem. 2001, 22, 216-229. Feldgus, S.; Shields, G. C. Chem. Phys. Lett. 2001, 347, 505-511.

(8) Logan, C. F.; Chen, P. J. Am. Chem. Soc. 1996, 118, 2113. Schottelius, M. J.; Chen, P. J. Am. Chem. Soc. 1996, 118, 4896.

(9) Schreiner, P. R. J. Am. Chem. Soc. 1998, 120, 4184. Schreiner, P. R. J. Chem. Soc., Chem. Commun. 1998, 483.

(10) For example: (a) Nagata, R.; Yamanaka, H.; Okazaki, E.; Saito, I. Tetrahedron Lett. 1989, 30, 4995. Myers, A. G.; Dragovich, P. S.; Kuo, E. Y. J. Am. Chem. Soc. 1992, 114, 9369. (b) Nakatani, K.; Isoe, S.; Maekawa, S.; Saito, I. Tetrahedron Lett. 1994, 35, 605. Sullivan, R. W.; Coghlan, V. M.; Munk, S. A.; Reed, M. W.; Moore, H. W. J. Org. Chem. 1994, 59, 2276. (c) Toda, F.; Tanaka, K.; Sano, I.; Isozaki, T. Angew. Chem., Int. Ed. Engl. 1994, 33, 1757.(d) Nicolaou, K. C.; Skokotas, G.; Maligres, P.; Zuccarello, G.; Schweiger, E. J.; Toshima, K.; Wendeborn, S. Angew. Chem., Int. Ed. Engl. 1989, 28, 1272. (e) Engels, B.; Lennartz, C.; Hanrath, M.; Schmittel, M.; Strittmatter, M. Angew. Chem., Int. Ed. 1998, 37, 2067. (f) Schmittel, M.; Steffen, J.-P.; Angel, M. A. W.; Engels, B.; Lennartz, C.; Hanrath, M. Angew. Chem., Int. Ed. 1998, 37, 2067. (g) Schmittel, M.; Rodriguez, D.; Steffen, J. P. Angew. Chem., Int. Ed. 2000, 39, 2067. (h) Kawatkar, S. P.; Schreiner, P. R. Org. Lett. 2002, 4, 3643.

(11) Galbraith, J. M.; Schreiner, P. R.; Harris, N.; Wei, W.; Wittkopp, A.; Shaik, S. Chem.-Eur. J. 2000, 6, 1446.
(12) A similar conclusion was also reached by Gleiter and Haberhauer: Haberhauer, G.; Gleiter, R. J. Am. Chem. Soc. 1999, 121, 4664-4668.

(13) Stahl, F.; Moran, D.; Schleyer, P. v. R.; Prall, M.; Schreiner, P. R. J. Org. Chem. 2002, 67, 1453.

(14) A very interesting recent paper also evaluated magnetic properties and aromaticity of $o^{-}, m-$, and $p$-benzynes within a series of aromatic indicators such as magnetic susceptibility anisotropies and exaltations, nucleus-independent chemical shift, and aromatic stabilization energies. The authors arrived at a similar conclusion that $\pi$-delocalization is dominant in the TS. De Proft, F.; Schleyer, P. v. R.; Lenthe, J. v. H.; Stahl, F.; Geerlings, P. Chem.-Eur. J. 2002, 8, 3405 .

(15) Glendening, E. D.; Badenhoop, J. K.; Reed, A. E.; Carpenter, J. E.; Weinhold, F. F. NBO 4.0; Theoretical Chemistry Institute, University of Wisconsin: Madison, WI, 1996.

(16) Grafenstein, J.; Hjerpe, A. M.; Kraka, E.; Cremer, D. J. Phys. Chem. A 2000, 104, 1748.

(17) Frisch, M. J.; Trucks, G. W.; Schlegel, H. B.; Scuseria, G. E.; Robb, M. A.; Cheeseman, J. R.; Zakrzewski, V. G.; Montgomery, J. A., Jr.; Stratmann, R. E.; Burant, J. C.; Dapprich, S.; Millam, J. M.; Daniels, A. D.; Kudin, K. N.; Strain, M. C.; Farkas, O.; Tomasi, J.; Barone, V.; Cossi, M.; Cammi, R.; Mennucci, B.; Pomelli, C.; Adamo, C.; Clifford, S.; Ochterski, J.; Petersson, G. A.; Ayala, P. Y.; Cui, Q.; Morokuma, K.; Malick, D. K.; Rabuck, A. D.; Raghavachari, K.; Foresman, J. B.; Cioslowski, J.; Ortiz, J. V.; Stefanov, B. B.; Liu, G.; Liashenko, A.; Piskorz, P.; Komaromi, I.; Gomperts, R.; Martin, R. L.; Fox, D. J.; Keith, T.; Al-Laham, M. A.; Peng, C. Y.; Nanayakkara, A.; Gonzalez, C.; Challacombe, M.; Gill, P. M. W.; Johnson, B. G.; Chen, W.; Wong, M. W.; Andres, J. L.; Head-Gordon, M.; Replogle, E. S.; Pople, J. A. Gaussian 98; Revision A.9; Gaussian, Inc.: Pittsburgh, PA, 1998.

(18) For the most recent thorough discussion of relative advantages and disadvantages of different DFT methods for description of cycloaromatization reactions, see: Prall, M.; Wittkopp, A.; Schreiner, P. R. J. Phys. Chem. A 2001, 105, 9265.

(19) Foster, J. P.; Weinhold, F. F. J. Am. Chem. Soc. 1980, 102, 7211 Reed A. E.; Weinhold, F. F. J. Chem. Phys. 1983, 78, 4066. Reed, A. E.; Weinstock, F.; Weinhold, F. F. J. Chem. Phys. 1985, 83, 735. Reed, A. E.; Curtiss, L. A.; Weinhold, F. F. Chem. Rev. 1988, 88, 899. Weinhold F. In Encyclopedia of Computational Chemistry; Schleyer, P. v. R., Ed.; Wiley: New York, 1998, Vol. 3, p 1792.

(20) See the following references as representative examples: Weinhold, F. J. Mol. Struct. (THEOCHEM) 1997, 398, 18. Alabugin, I. V. J. Org. Chem. 2000, 65, 3910. Alabugin, I. V.; Zeidan, T. A. J. Am. Chem. Soc. 2002, 124, 3175 .

(21) The relative magnitudes of the changes in the in-plane and outof-plane $\pi$-systems in the TS has been also analyzed with VB theory in ref 11. Our analysis is consistent with these results but provides more detail because it operates at the level of individual $\pi$ - and $\sigma$-bonds and determines the importance of both attractive and repulsive interactions.

(22) Nicolaou, K. C.; Zuccarello, G.; Riemer, C.; Estevez, V. A.; Dai, W.-M. J. Am. Chem. Soc. 1992, 114, 7360.

(23) Later Schreiner expanded the C1-C6 range to 3.4-2.9 A using DFT computations (see ref 9 ).

(24) Kraka, E.; Cremer, D. J. Am. Chem. Soc. 1994, 116, 4929.

(25) The calculated $\mathrm{C} 1-\mathrm{C} 6$ distance in $\mathbf{1}$ is similar to the experimental value of $4.32 \AA$ in: McMahon, R. J.; Halter, R. J.; Fimmen, R. L.; Wilson, R. J.; Peebles, S. A.; Kuczkowski, R. L.; Stanton, J. F. J. Am. Chem. Soc. 2000, 122, 939. Small deviation is consistent with the relatively soft potential for acetylene bending.

(26) This observation indicates the presence of a factor that destabilizes the TS and the product of the Bergman cyclization of enediyne 2. Most likely, the TS destabilization stems from the properties of the polymethylene bridge that locks the terminal acetylene atoms in the 10-membered cycle.

(27) Koga, N.; Morokuma, K. J. Am. Chem. Soc. 1991, 113, 1907.

(28) Minkin, V. I.; Glukhovtsev, M. N.; Simkin, B. Y. Aromaticity and Antiaromaticity - Electronic and Structural Aspects; John Wiley \& Sons: New York, 1994. See also: Chem. Rev. 2001, 101, thematic issue, Aromaticity (Schleyer, P. v. R., Ed.).

(29) Malandra, J. L.; Mills, N. S.; Kadlecek, D. E.; Lowery, J. A. J. Am. Chem. Soc. 1994, 116, 11622. Mills, N. S.; Malandra, J. L.; Burns, E. E.; Green, A.; Unruh, K. E.; Kadlecek, D. E.; Lowery, J. A. J. Org. Chem. 1997, 62, 9318. Mills, N. S.; Burns, E. B.; Hodges, J.; Gibbs, J.; Esparza E.; Malandra, J. L.; Koch, J. J. Org. Chem. 1998, 63, 3017. Mills, N. S.; Malinky, T.; Malandra, J. L.; Burns, E. E.; Crossno, P. J. Org. Chem. 1999, 64, 511. Mills, N. S. J. Am. Chem. Soc. 1999, 121, 11690. Mills, N. S.; Benish, M. M.; Rakowitz, A. J.; Bebell, L. M. J. Org. Chem. 2002, 67, 2003-2012.

(30) This is consistent with an earlier suggestion in ref 27.

(31) However, this effect is not large as illustrated by the NBO deletion analysis in which the energy of the $\pi_{\mathrm{i}}-\pi_{\mathrm{i}}^{*}$ interaction is estimated by deletion of the corresponding $F_{i, j}$ elements followed by recalculation of the total energy (Figure 6). According to the NBO deletions, the energy of the $\pi_{\mathrm{i}}-\pi_{\mathrm{i}} *$ interactions in enediyne 1 is only $0.5 \mathrm{kcal} / \mathrm{mol}$, and thus, the decrease in this stabilizing interaction in the ground states of the cyclic enediynes 2 
and $\mathbf{3}$ is only a minor component in the ground-state destabilization compared to the four-electron repulsion. Figure 5 also illustrates that the $\mathrm{C} 1-\mathrm{C} 6$ bond formation is of minor importance at the distances above 2.5 $\AA$ (in accord to the timing of the $\mathrm{C} 1-\mathrm{C} 2 / \mathrm{C} 5-\mathrm{C} 6 \pi$-bond breaking in Figure 3).

(32) Estimated by simultaneous deletion of the corresponding Fock matrix elements followed by variational recalculation of the wave function.

(33) The reaction barrier at the shorter distances is mainly a result of the $\mathrm{C} 1-\mathrm{C} 2(\mathrm{C} 5-\mathrm{C} 6) \pi$-bond breaking processes.

(34) Note that the NBOs can still be clearly matched to the original $\pi$ and $\sigma$-orbitals even in the TS. This is in a sharp contrast to Pipek-Mezey localized orbitals used for dissected NICS computations in ref 13. The Pipek-Mezey localized orbitals mix to the extent that the in-plane $\pi$ - and $\sigma$-systems become indistinguishable.

(35) Jafri, J. A.; Newton, M. D. J. Am. Chem. Soc. 1978, 100, 5012.

(36) Zimmerman, H. E. J. Am. Chem. Soc. 1966, 88, 1564. Zimmerman, H. E. Tetrahedron 1982, 38, 753. See also Bernardi, F.; Celani, P.; Olivucci, M.; Robb, M. A.; Suzzivalli, G. J. Am. Chem. Soc. 1995, 117, 10531.

(37) One can argue that the presence of the in-plane $\mathrm{C} 3-\mathrm{C} 4$ bond and the six-electron out-of-plane $\pi$-system renders the whole molecule nonantiaromatic in the strictest sense (and this is consistent with the results of our NICS computations, see the Supporting Information). Therefore, we use the quotation marks for the term "antiaromatic region". However, use of this term is justified because the lack of the $\pi-\pi^{*}$ stabilization along the strong $\pi-\pi$ repulsion provides an appealing analogy to antiaromatic molecules.

(38) Kagan, J.; Wang, X.; Chen, X.; Lau, K. Y.; Batac, I. V.; Tuveson, R. W.; Hudson. J. B J. Photochem. Photobiol., B: Biol. 1993, 21, 135142 .

(39) (a) Turro, N. J.; Evenzahav, A.; Nicolauo, K. C. Tetrahedron Lett. 1994, 15, 8089-8092. (b) Evenzahav, A.; Turro, N. J. J. Am. Chem. Soc. 1998, 120, 1835-1841.

(40) Funk, R. L.; Young, E. R. R.; Williams, R. M.; Flanagan, M. F.; Cecil, T. L. J. Am. Chem. Soc. 1996, 118, 3291-3292.

(41) Choy, N.; Blanco, B.; Wen, J.; Krishan, A.; Russell, K. C. Org. Lett. 2000, 2, 3761-3764.

(42) Jones, G. B.; Wright, J. M.; Plourde, G., II;. Purohit, A. D.; Wyatt,

J. K.; Hynd, G.; Fouad, F. J. Am. Chem. Soc. 2000, 122, 9872-9873.

(43) Kaneko, T.; Takanashi, M.; Hirama, M. Angew. Chem., Int. Ed. 1999, $38,1267-1268$.

(44) Note also several reports of indirect, photochemically triggered, but thermal Bergman cycloaromatizations. (a) Wender, P. A.; Zercher, C. K.; Beckham, S.; Haubold, E.-M. J. Org. Chem. 1993, 58, 5867-5869. Wender, P. A.; Beckham, S.; O'Leary, J. G. Synthesis 1994, 1278. (b) Nicolauo, K. C.; Dai, W. M.; Wendeborn, S. V.; Smith, A. L.; Torisawa, Y.; Maligres, P.; Hwang, C. K. Angew. Chem., Int. Ed. Engl. 1991, 30 1032. (c) Nakatani, K.; Isoe, S.; Maekawa, S.; Saito, I. Tetrahedron Lett. 1994, 35, 605. Nakatani, K.; Maekawa, S.; Tanabe, K.; Saito, I. J. Am.
Chem. Soc. 1995, 117, 10635. (d) Basak, A.; Moh'd Bdour, H.; Shain, J. S.; Mandal, S.; Rudra, K. R.; Nag, S. Bioorg. Med. Chem. Lett. 2000, 10 1321. Two attempts resulted in only cis - trans isomerization (UV, $366 \mathrm{~nm}$ ). (e) Reference 38. (f) Konig, B.; Schofield, E.; Bubenitschek, P.; Jones, P. G. J. Org. Chem. 1994, 59, 7142. Photosensitized electron-transfer reactions of aromatic enediynes are known, but they proceed via mechanisms different from the Bergman cyclization. Cyclization of radical cations: (g) Ramkumar, D.; Kalpana, M.; Varghese, B.; Sankararaman, S. J. Org. Chem. 1996 61, 2247. Cyclization of radical anions: (h) Alabugin, I. V.; Kovalenko, S. V. J. Am. Chem. Soc. 2002, 124, 9052.

(45) The thermal Bergman cyclization is also a symmetry-allowed process as a result of the through-bond coupling of the two radical centers. See, for example, ref 11 for a discussion.

(46) Clark, A. E.; Davidson, E. R.; Zaleski, J. M. J. Am. Chem. Soc. 2001, 123, 2650 .

(47) The MO energies were estimated from the B3LYP/6-31G** computations for the reactant and B3LYP/6-31G**//UB3LYP/6-31G** for the TS and the product. Because of the ongoing discussion about the physical meaning of "DFT MOs", we would like to stress that we restrict ourselves in use of this correlation diagram only to the qualitative discussions.

(48) Prall, M.; Wittkopp, A.; Fokin, A. A.; Schreiner, P. R. J. Comput. Chem. 2001, 22, 1605. Note, however, that in this case the reaction thermodynamics is largely controlled by the Bent's rule-reactants (fluoroacetylenes) are destabilized relative to the products (fluorobenzenes) because it is intrinsically more favorable to have an electronegative substituent attached to an $\mathrm{sp}^{2}$ rather than to an $\mathrm{sp}$ atom.

(49) Jones, G. B.; Plourde, G. W. Org. Lett. 2000, 2, 1757. See also: Jones, G. B.; Warner, P. M. J. Am. Chem. Soc. 2001, 123, 2134.

(50) Alabugin, I. V.; Manoharan, M.; Kovalenko, S. V. Org. Lett. 2002, $4,1119$.

(51) Osinsky, S. P.; Levitin, I. Y.; Bubnovskaya, L. N.; Ganusevich, I. I.; Sigan, A. L.; Tsykalova, M. V.; Zagorujko, L. I. Exp. Oncol. 1999, 21 , 216. Tannock, I. F,: Rotin, D. Cancer Res. 1989, 49, 4373.

(52) Kraka, E.; Cremer, D. J. Am. Chem. Soc. 2000, 122, 2245.

(53) Hoffner, J.; Schottelius, J.; Feichtinger, D.; Chen, P. J. Am. Chem. Soc. 1998, 120, 376-385.

(54) The relative magnitude of the sum of the $F_{i j}$ terms corresponding to the two attractive $\pi-\pi^{*}$ interactions $\left(\pi_{\mathrm{ClC} 2} \rightarrow \pi^{*}{ }_{\mathrm{C} 5 \mathrm{C} 6}\right.$ and $\pi_{\mathrm{C} 5 \mathrm{C} 6} \rightarrow$ $\left.\pi^{*}{ }_{\mathrm{C} 1 \mathrm{C} 2}\right)$ does not change significantly compared to 1,2-diethynyl benzene. An increase in donation from the remote in-plane $\pi$-bond to the $\pi$-bond adjacent to the electron acceptor $\left(\pi_{\mathrm{C} 5 \mathrm{C} 6} \rightarrow \pi^{*}{ }_{\mathrm{C} 1 \mathrm{C} 2}\right)$ is partially compensated by a decrease in the donation from the opposite direction $\left(\pi_{\mathrm{C} 1 \mathrm{C} 2} \rightarrow \pi^{*}{ }_{\mathrm{C} 5 \mathrm{C} 6}\right)$. Interestingly, when the same donations are analyzed using the more rigorous NBO deletion procedure, the combined energy of $\pi_{\mathrm{C} 5 \mathrm{C} 6} \rightarrow \pi^{*}{ }_{\mathrm{C} 1 \mathrm{C} 2}$ and $\pi_{\mathrm{C} 1 \mathrm{C} 2}$ $\rightarrow \pi^{*}{ } 5 \mathrm{C} 6$ in the protonated aniline $\mathbf{6}$ is significantly larger than that in 1,2-diethynyl benzene indicating than the $\pi \rightarrow \pi^{*}$ bonding interactions are also increased in the TS for the Bergman cyclization of $\mathbf{6}$.

(55) Alabugin, I. V.; Manoharan, M., manuscript in preparation. 